\title{
Pharmacist-led Antimicrobial Stewardship
}

\author{
Abdul Kader Mohiuddin* \\ Assistant Professor, Department of Pharmacy, World University of Bangladesh \\ *Corresponding Author: Abdul Kader Mohiuddin, Assistant Professor, Department of Pharmacy, World \\ University of Bangladesh
}

Respected sir,

The estimation of basic consideration pharmacists has been very much archived. Different examinations have appeared basic consideration pharmacists diminish medication blunders, improve patient results, lessen expenses and waste, and reduction death rates among patients with thromboembolic maladies or contaminations [1,2]. Antimicrobial opposition (AMR) causes prolonged sickness, more serious danger of disease spread, expanded bleakness, and higher death rates, which result in expanded costs to the administration, medicinal services administrations, and people. It is evaluated that around 700,000 individuals kick the bucket every year from drug-safe diseases, with specialists foreseeing a disturbing conceivable increment to 10 million passings every year by 2050 and significant future difficulties to the manner in which we practice medication and medical procedure. Opposition has been related with expanding mortality, treatment disappointment and medicinal services costs $[3,4]$. This disturbing rate surpasses the yearly number of passings brought about by disease ( 8.2 million) and is right around multiple times that of engine vehicle mishaps (1.2 million) [5]. In the United States, notwithstanding huge mortality, antimicrobial opposition includes \$20 billion in overabundance direct medicinal services costs and up to $\$ 35$ billion in yearly societal expenses because of lost efficiency [6]. Antiinfection stewardship was set up to battle this pattern and was perceived in 1996 to attract regard for the rising episodes in mortality and dismalness related with unseemly utilization of anti-toxins [7]. Antiinfection stewardship is a center piece of basic consideration, and ordinarily, the doctor will depend on the pharmacist's proposals and skill. Anti-toxin Stewardship Recommendations incorporate establishing a group, close coordination between groups, review, model limitation, de-acceleration, improving dosing, dynamic utilization of data innovation among other measure [8]. The Infectious Diseases Society of America rules on antimicrobial stewardship suggest that the center multidisciplinary stewardship group incorporate an irresistible ailments (ID) doctor and a clinical pharmacist with ID preparing [9]. Anti-infection recommending in outpatient settings surpasses that of inpatient endorsing, with in excess of 150 million anti-infection medicines every year; of these solutions, over $30 \%$ are either pointless or improperly endorsed [10-12]. Orally managed antimicrobials represented roughly $90 \%$ of all out utilization: oral third-age cephalosporins, macrolides, and fluoroquinolones represented around $77 \%$ of oral utilization. Thusly, pharmacists must broaden their help for the suitable utilization of antimicrobials recommended by going to doctors to hospitalized patients as well as outpatients [13]. As the guidelines for anti-infection stewardship in outpatient settings proceed to develop and ideal stewardship systems are characterized, pharmacists must be pioneers in the execution of these projects [14]. Stewardship projects can help, diminish wrong solution and wide range utilization of antimicrobials, improve, clinical results for the populace in general, hinder the rise of antimicrobial opposition and moderate medicinal services assets [3]. The WHO Global Action Plan on Antimicrobial Resistance prescribes nations cooperate to improve mindfulness and comprehension of antimicrobial opposition, including through online networking. The 2018 World Antibiotic Awareness Week battle utilized Twitter to tailor media messages about the Global Action Plan [15]. Web-based social networking have turned out to be significant data channels, yet may not contact individuals with low learning and additionally low enthusiasm for the subject. Inside the EU, nations with low utilization of anti-toxins, for example, Sweden and The Netherlands, demonstrate a higher populace learning level [16]. The utilization of network anti-infection stewardship programs (ASPs) is rising. ASPs including pharmacists are powerful in diminishing anti-microbial recommending and expanding rule disciple anti- 
infection endorsing by GPs [17]. Proof in China and Netherlands demonstrated that anti-infection stewardship program was related with over $80 \%$ and over $25 \%$ reduction in expense of anti-toxin prophylaxis per technique individually [18]. The issue of antimicrobial obstruction is more regrettable in low and center pay nations (LMIC), as the frequency of irresistible infections is high contrasted with high-pay nations. In low and center pay nations, the death rates because of antimicrobial-safe microscopic organisms are under-announced, in any case, accessible information in India, Nigeria, Pakistan, and Congo show that countless neonatal passings came about because of drug-safe sepsis [19]. Every year, in excess of 50,000 infants are evaluated to bite the dust from sepsis because of pathogens impervious to first-line anti-toxins [20]. In European nations, antimicrobial obstruction is likewise on the ascent and viewed as in charge of around 25,000 passings yearly [21]. Pharmacists are center AMS colleagues where there is a progressing need to adjust proceeding with instruction for wellbeing experts to substances of training. In any case, antimicrobial stewardship (AMS) isn't exhaustively and completely instructed in restorative or pharmacy educational programs and little is thought about the importance of pharmacist preparing to address AMS issues [22]. Fundamentally, there is a requirement for building up economical financing for AMS groups working past emergency clinic settings that isn't exclusively gotten from cost investment funds through decreased drug use. Rather, subsidizing for developing and supporting AMS groups ought to be considered inside the patient security and social insurance quality-related burning through [23]. All the more as of late, the presentation of national stewardship rules, and an expanded spotlight on stewardship as a major aspect of the UK five-year antimicrobial obstruction methodology, have quickened and inserted improvements. Antimicrobial pharmacists have been instrumental in affecting changes at a hierarchical and national level [24]. A pharmacist apportioning antimicrobials without a remedy is $83-100 \%$ of the time unconscious of a patient's hypersensitivities status [19]. Erroneous sensitivity marking results in wrong antimicrobial administration of the patient, which may influence clinical result, increment the danger of unfavorable occasions and increment costs. Improper utilization of elective anti-toxins has suggestions for antimicrobial stewardship programs and microbial obstruction. du Plessis et.al, 2019 prescribed that a pharmacist-drove hypersensitivity the executives administration is a protected choice to advance antimicrobial stewardship and suitable sensitivity naming [25]. Cheon et.al, 2018 proposed more extensive appropriation for the job of pharmacists in the arrangement of penicillin skin testing. This would help grow the administration and expand the potential advantages of penicillin skin testing [26]. Pharmacists might be entrusted to lead ASP advancement and usage with almost no help from an irresistible illnesses (ID) doctor and other emergency clinic faculty whose association on ASP groups is prescribed (e.g., clinical microbiologists, contamination control pros, medical clinic disease transmission specialists) [27]. Pharmacists and other human services experts ought to work together inside multidisciplinary groups (MDTs) to lessen the danger of antimicrobial opposition, subsequently decreasing the monetary weight, improving patients' personal satisfaction, and diminishing hospitalization because of contaminations [19]. In a UK consider, practically $60 \%$ of pharmacist's commitments are made during the MDT round [28]. Research has demonstrated that pharmacists assume a significant job in the (Emergency Department) ED, yet there is a requirement for information supporting this in explicit patient results as most of the writing tends to unfavorable drug occasion avoidance and cost-regulation [29]. Basic consideration pharmacists are perceived in the rules from the Society of Critical Care Medicine (SCCM) as fundamental colleagues for the conveyance of consideration for basically sick patients. Truth be told, the arrival on venture of an ICU pharmacist's pay drew closer in different investigations of basically sick patients with disease [30]. Counting basic consideration pharmacists in the multidisciplinary ICU group improved patient results including mortality, ICU length of remain in blended ICUs, and preventable/nonpreventable antagonistic drug occasions [31]. In spite of the fact that factors, for example, an absence of monetary assets, might be outside the ability to control of the pharmacy calling, different components, for example, expanded documentation in patient records and expanded insightful work showing pharmacists' commitments, can and ought to be tended to all the more reliably by all basic consideration pharmacists [32]. The basic consideration pharmacist guarantees the cessation of these medications in patients who never again have a sign. Shockingly, these medications are now and again begun by the ward group and proceeded on release. Furthermore, home support medications are frequently not continued on clinic confirmation as well as resulting release, expanding the danger of death, emergency department visit, or hospitalization. A basic consideration pharmacist coordinated into the ICU-Recovery Center (ICU$\mathrm{RC}$ ) may take endeavor to recognize and treat the sorts of medication blunders found in a populace of high-hazard ICU [33]. Moreover, pharmacists who are regularly the primary purpose of consideration, 
administer anti-microbials without a doctor solution, offer elective anti-microbials notwithstanding when patients present with a remedy. Inside the clinics absence of observing of anti-infection use is one of the central point driving the spread of opposition [34]. The execution of antimicrobial stewardship programs in essential social insurance is problematic. This contrarily influences the worldwide endeavors to control antimicrobial opposition. There is a need to regulate national rules for AMS in essential medicinal services [35]. Different randomized controlled preliminaries (RCTs) have discovered that shorter courses of anti-microbial treatment result in comparative fix rates as customary courses for some kinds of contaminations, including UTIs, SSTIs, and pneumonia. Tragically, recognition with short-course treatment as a stewardship device is restricted. An ongoing report found that only 33\% of irresistible maladies experts from 58 nations suggested short-course treatments [36]. Subsequently, a few nations have prescribed shortening the span of anti-toxin treatment of network obtained pneumonia (CAP). No huge contrasts in unfriendly occasions were accounted for. Be that as it may, none of the preliminaries gave an account of the effect on the improvement of safe microscopic organisms [37]. Similarly as with the expense of environmental change, assessments of all out AMR expenses are loaded with vulnerability and might be excessively low. This expense relies upon different variables: which drug and pathogen are included, the component of anti-toxin opposition, the pervasiveness of that pathogen, the kinds of diseases it causes and their degree of transmissibility, the wellbeing weight of those contaminations, and whether elective medications are accessible [38]. AMS can enable pharmacists to improve the nature of patient consideration and improve patient wellbeing through expanded disease fix rates, diminished treatment disappointments, and expanded recurrence of right recommending for treatment and prophylaxis. The expense of utilizing a pharmacist at the suggested least staffing level is around $£ 20$ per patient every day. A few examinations find that the job diminishes by and large consumption through progressively proficient utilization of medications and the shirking of direct expenses of iatrogenic mischief, with extra investment funds produced using maintaining a strategic distance from payouts emerging from harms claims [19], [27].

\section{REFERENCES}

[1] Mohiuddin AK. Pharmacists in Critical Care. INNOVATIONS in pharmacy, 2019, Vol. 10, No. 1, Article 8. DOI: https://doi.org/10.24926/iip.v10i1.1640

[2] Chant C. How critical are critical care pharmacists? Can J Hosp Pharm. 2012 Jan;65(1):5-6. PubMed PMID: 22479105; PubMed Central PMCID: PMC3282202.

[3] Garau J, Bassetti M. Role of pharmacists in antimicrobial stewardship programmes. Int J Clin Pharm. 2018 Oct;40(5):948-952. doi: 10.1007/s11096-018-0675-z. Epub 2018 Sep 22. Review. PubMed PMID: 30242589.

[4] McLeod M, Ahmad R, Shebl NA, Micallef C, Sim F, Holmes A. A whole-health-economy approach to antimicrobial stewardship: Analysis of current models and future direction. PLoS Med. 2019 Mar 29;16(3):e1002774. doi: 10.1371/journal.pmed.1002774. eCollection 2019 Mar. PubMed PMID: 30925166; PubMed Central PMCID: PMC6440619.

[5] Fay LN, Wolf LM, Brandt KL, DeYoung GR, Anderson AM, Egwuatu NE, Dumkow LE. Pharmacist-led antimicrobial stewardship program in an urgent care setting. Am J Health Syst Pharm. 2019 Jan 25;76(3):175-181. doi: 10.1093/ajhp/zxy023. PubMed PMID: 30689745; PubMed Central PMCID: PMC6366123.

[6] Centers for Disease Control and Prevention. Antibiotic resistance threats in the United States, 2013 https://www.cdc.gov/drugresistance/threat-report-2013/pdf/ar-threats-2013-508.pdf (accessed 2018 May $15)$.

[7] Habboush Y, Guzman N. Antibiotic Resistance. [Updated 2018 Nov 23]. In: StatPearls [Internet]. Treasure Island (FL): StatPearls Publishing; 2019 Jan-. Available from: https://www.ncbi.nlm.nih.gov/books/NBK513277/

[8] Friedrich AW. Control of hospital acquired infections and antimicrobial resistance in Europe: the way to go. Wien Med Wochenschr. 2019 Feb;169(Suppl 1):25-30. doi: 10.1007/s10354-018-0676-5. Epub 2019 Jan 8. PubMed PMID: 30623278; PubMed Central PMCID: PMC6373234.

[9] Bessesen MT, Ma A, Clegg D, Fugit RV, Pepe A, Goetz MB, Graber CJ. Antimicrobial Stewardship Programs: Comparison of a Program with Infectious Diseases Pharmacist Support to a Program with a Geographic Pharmacist Staffing Model. Hosp Pharm. 2015 Jun;50(6):477-83. doi: 10.1310/hpj5006-477. PubMed PMID: 26405339; PubMed Central PMCID: PMC4568108.

[10] Suda KJ, Hicks LA, Roberts RM, Hunkler RJ, Danziger LH. A national evaluation of antibiotic expenditures by healthcare setting in the United States, 2009. J Antimicrob Chemother. 2013 Mar;68(3):715-8. doi: 10.1093/jac/dks445. Epub 2012 Nov 11. PubMed PMID: 23148204. 
[11] Fleming-Dutra KE, Hersh AL, Shapiro DJ, Bartoces M, Enns EA, File TM Jr, Finkelstein JA, Gerber JS, Hyun DY, Linder JA, Lynfield R, Margolis DJ, May LS, Merenstein D, Metlay JP, Newland JG, Piccirillo JF, Roberts RM, Sanchez GV, Suda KJ, Thomas A, Woo TM, Zetts RM, Hicks LA. Prevalence of Inappropriate Antibiotic Prescriptions Among US Ambulatory Care Visits, 2010-2011. JAMA. 2016 May 3;315(17):1864-73. doi: 10.1001/jama.2016.4151. PubMed PMID: 27139059.

[12] Centers for Disease Control and Prevention. Outpatient antibiotic prescriptions-United States, 2014 https://www.cdc.gov/antibiotic-use/community/pdfs/annual-reportsummary_2014.pdf

[13] Muraki Y. [The Role of Pharmacists in Antimicrobial Stewardship]. Yakugaku Zasshi. 2019;139(4):557564. doi: 10.1248/yakushi.18-00181-3. Review. Japanese. PubMed PMID: 30930388.

[14] Blanchette L, Gauthier T, Heil E, Klepser M, Kelly KM, Nailor M, Wei W, Suda K; Outpatient Stewardship Working Group. The essential role of pharmacists in antibiotic stewardship in outpatient care: An official position statement of the Society of Infectious Diseases Pharmacists. J Am Pharm Assoc (2003). 2018 Sep - Oct;58(5):481-484. doi: 10.1016/j.japh.2018.05.013. Epub 2018 Jul 13. PubMed PMID: 30007508.

[15] Goff DA, Kullar R, Laxminarayan R, Mendelson M, Nathwani D, Osterholm M. Twitter to engage, educate, and advocate for global antibiotic stewardship and antimicrobial resistance. Lancet Infect Dis. 2019 Mar;19(3):229-231. doi: 10.1016/S1473-3099(19)30058-1. PubMed PMID: 30833049.

[16] Waaseth M, Adan A, Røen IL, Eriksen K, Stanojevic T, Halvorsen KH, Garcia BH, Holst L, Ulshagen KM, Blix HS, Ariansen H, Nordeng HME. Knowledge of antibiotics and antibiotic resistance among Norwegian pharmacy customers - a cross-sectional study. BMC Public Health. 2019 Jan 15;19(1):66. doi: 10.1186/s12889-019-6409-x. PubMed PMID: 30646892; PubMed Central PMCID: PMC6332570.

[17] Saha SK, Hawes L, Mazza D. Effectiveness of interventions involving pharmacists on antibiotic prescribing by general practitioners: a systematic review and meta-analysis. J Antimicrob Chemother. 2019 Jan 28. doi: 10.1093/jac/dky572. [Epub ahead of print] PubMed PMID: 30698721.

[18] Abubakar U, Syed Sulaiman SA, Adesiyun AG. Impact of pharmacist-led antibiotic stewardship interventions on compliance with surgical antibiotic prophylaxis in obstetric and gynecologic surgeries in Nigeria. PLoS One. 2019 Mar 7;14(3):e0213395. doi: 10.1371/journal.pone.0213395. eCollection 2019. PubMed PMID: 30845240; PubMed Central PMCID: PMC6405127.

[19] Rehman IU, Asad MM, Bukhsh A, Ali Z, Ata H, Dujaili JA, Blebil AQ, Khan TM. Knowledge and Practice of Pharmacists toward Antimicrobial Stewardship in Pakistan. Pharmacy (Basel). 2018 Oct 23;6(4). pii: E116. doi: 10.3390/pharmacy6040116. PubMed PMID: 30360517; PubMed Central PMCID: PMC6306925.

[20] Dixit A, Kumar N, Kumar S, Trigun V. Antimicrobial Resistance: Progress in the Decade since Emergence of New Delhi Metallo- $\beta$-Lactamase in India. Indian J Community Med. 2019 Jan-Mar;44(1):4-8. doi: 10.4103/ijcm.IJCM_217_18. PubMed PMID: 30983704; PubMed Central PMCID: PMC6437806.

[21] European Commission Antimicrobial Resistance 2017. [(accessed on 10 July 2017)]; Antimicrobial Resistance. Available online: https://ec.europa.eu/health/amr/antimicrobial-resistance_en.

[22] Nasr ZG, Higazy A, Wilbur K. Exploring the gaps between education and pharmacy practice on antimicrobial stewardship: a qualitative study among pharmacists in Qatar. Adv Med Educ Pract. 2019 May 6;10:287-295. doi: 10.2147/AMEP.S198343. eCollection 2019. Erratum in: Adv Med Educ Pract. 2019 May 23;10:307. PubMed PMID: 31191076; PubMed Central PMCID: PMC6511628.

[23] Pulcini C, Morel CM, Tacconelli E, Beovic B, de With K, Goossens H, Harbarth S, Holmes A, Howard P, Morris AM, Nathwani D, Sharland M, Schouten J, Thursky K, Laxminarayan R, Mendelson M. Human resources estimates and funding for antibiotic stewardship teams are urgently needed. Clin Microbiol Infect. 2017 Nov;23(11):785-787. doi: 10.1016/j.cmi.2017.07.013. Epub 2017 Aug 2. PubMed PMID: 28778544.

[24] Gilchrist M, Wade P, Ashiru-Oredope D, Howard P, Sneddon J, Whitney L, Wickens H. Antimicrobial Stewardship from Policy to Practice: Experiences from UK Antimicrobial Pharmacists. Infect Dis Ther. 2015 Sep;4(Suppl 1):51-64. doi: 10.1007/s40121-015-0080-z. Epub 2015 Sep 11. PubMed PMID: 26362295; PubMed Central PMCID: PMC4569645.

[25] du Plessis T, Walls G, Jordan A, Holland DJ. Implementation of a pharmacist-led penicillin allergy delabelling service in a public hospital. J Antimicrob Chemother. 2019 Feb 6. doi: 10.1093/jac/dky575. [Epub ahead of print] PubMed PMID: 30753497.

[26] Cheon E, Horowitz HW. New Avenues for Antimicrobial Stewardship: The Case for Penicillin Skin Testing by Pharmacists. Clin Infect Dis. 2019 May 30;68(12):2123-2124. doi: 10.1093/cid/ciy828. PubMed PMID: 30281071 .

[27] Waters CD. Pharmacist-driven antimicrobial stewardship program in an institution without infectious diseases physician support. Am J Health Syst Pharm. 2015 Mar 15;72(6):466-8. doi: 10.2146/ajhp140381. PubMed PMID: 25736941. 
[28] Borthwick M. The role of the pharmacist in the intensive care unit. J Intensive Care Soc. 2019 May;20(2):161-164. doi: 10.1177/1751143718769043. Epub 2018 Apr 23. PubMed PMID: 31037109; PubMed Central PMCID: PMC6475995.

[29] Baker SN, Acquisto NM, Ashley ED, Fairbanks RJ, Beamish SE, Haas CE. Pharmacist-managed antimicrobial stewardship program for patients discharged from the emergency department. J Pharm Pract. 2012 Apr;25(2):190-4. doi: 10.1177/0897190011420160. Epub 2011 Nov 17. PubMed PMID: 22095578; PubMed Central PMCID: PMC3533486.

[30] Bauer SR, Kane-Gill SL. Outcome Assessment of Critical Care Pharmacist Services. Hosp Pharm. 2016 Jul;51(7):507-13. doi: 10.1310/hpj5107-507. PubMed PMID: 27559182; PubMed Central PMCID: PMC4981097.

[31] Lee H, Ryu K, Sohn Y, Kim J, Suh GY, Kim E. Impact on Patient Outcomes of Pharmacist Participation in Multidisciplinary Critical Care Teams: A Systematic Review and Meta-Analysis. Crit Care Med. 2019 May 24. doi: 10.1097/CCM.0000000000003830. [Epub ahead of print] PubMed PMID: 31135496.

[32] Chant C. How critical are critical care pharmacists? Can J Hosp Pharm. 2012 Jan;65(1):5-6. PubMed PMID: 22479105; PubMed Central PMCID: PMC3282202.

[33] Stollings JL, Bloom SL, Wang L, Ely EW, Jackson JC, Sevin CM. Critical Care Pharmacists and Medication Management in an ICU Recovery Center. Ann Pharmacother. 2018 Aug;52(8):713-723. doi: 10.1177/1060028018759343. Epub 2018 Feb 18. PubMed PMID: 29457491; PubMed Central PMCID: PMC6039256.

[34] Barker AK, Brown K, Ahsan M, Sengupta S, Safdar N. What drives inappropriate antibiotic dispensing? A mixed-methods study of pharmacy employee perspectives in Haryana, India. BMJ Open. 2017 Mar 2;7(3):e013190. doi: 10.1136/bmjopen-2016-013190. PubMed PMID: 28255093; PubMed Central PMCID: PMC5353334.

[35] Brinkmann I, Kibuule D. Effectiveness of antibiotic stewardship programmes in primary health care settings in developing countries. Res Social Adm Pharm. 2019 Mar 16. pii: S1551-7411(19)30172-X. doi: 10.1016/j.sapharm.2019.03.008. [Epub ahead of print] PubMed PMID: 30904409.

[36] Yadav K, Masuda E, Minejima E, Spellberg B. Expected Practice as a Novel Antibiotic Stewardship Intervention. Open Forum Infect Dis. 2018 Dec 3;6(1):ofy319. doi: 10.1093/ofid/ofy319. eCollection 2019 Jan. PubMed PMID: 30631789; PubMed Central PMCID: PMC6324551.

[37] Møller Gundersen K, Nygaard Jensen J, Bjerrum L, Hansen MP. Short-course vs long-course antibiotic treatment for community-acquired pneumonia: A literature review. Basic Clin Pharmacol Toxicol. 2019 May;124(5):550-559. doi: 10.1111/bcpt.13205. Epub 2019 Feb 21. Review. PubMed PMID: 30694600.

[38] Roope LSJ, Smith RD, Pouwels KB, Buchanan J, Abel L, Eibich P, Butler CC, Tan PS, Walker AS, Robotham JV, Wordsworth S. The challenge of antimicrobial resistance: What economics can contribute. Science. 2019 Apr 5;364(6435). pii: eaau4679. doi: 10.1126/science.aau4679. Review. PubMed PMID: 30948524.

Citation: Abdul Kader Mohiuddin (2019). Pharmacist-led Antimicrobial Stewardship. ARC Journal of Pharmaceutical Sciences (AJPS), 5(3), pp.7-11. DOI: http://dx.doi.org/10.20431/2455-1538.0503002

Copyright: (c) 2019 Authors. This is an open-access article distributed under the terms of the Creative Commons Attribution License, which permits unrestricted use, distribution, and reproduction in any medium, provided the original author and source are credited. 